DOI: 10.1515/ijek-2016-0005

\title{
SELF SERVICE TECHNOLOGIES: A CAUSE OF UNEMPLOYMENT
}

\author{
Cathy-Austin OTEKHILE ${ }^{1}$, Milan ZELENY
}

\begin{abstract}
The self-service technologies(SSTs) are fast changing the conventional way of transacting business by business organisations. The rapid innovation of self-service technologies and its adoption and usages in all facets of human systems is acclaimed to be fast rendering low skilled workers jobless. The major sectors of the economy in advanced economies have reached their peaks and can no longer provide new employment due to an increase in the productivity growth rate as a result of technology advances. These SSTs have in no small measure brought about an increase in productivity growth rate, cost reduction and anincrease in the speed of service delivery to customers. This paper examines if self-service technologies truly are the cause of persistent unemployment through a study of the long term metamorphosis of the major economic sectors in advanced economies. This study revealed that the SSTs presents both risks and opportunities.
\end{abstract}

\section{INTRODUCTION}

He who rejects change is an architect of decay. The only human institution which rejects progress is the cemetery-Harold WilsonSpeech to the Consultative Assembly of the Council of Europe, Strasbourg, France 23 ${ }^{\text {rd }}$ January, 1967.

In this dynamic world, almost everything is changing, from human systems to the environment. The emergence of self-service technologies is rapidly replacing the traditional way of business and service delivery at an accelerating rate in both advanced and developing economies. Although some developing economies still have a long way to go with regards to industrialization and the need to expand their service industry. Every rational economic agent is relatively seeking cheaper means of production of goods by substituting labor intensive goods for capital intensive goods and consumers in return will buy goods and services at their convenience and reasonable price. Some sectors and businesses are created or disrupted while new ones are created- corso and ricorso. (Schumpeter, 1942; Zeleny, 2010; Zeleny, 2012).

The Corso and Ricorso (C\&R) idea(Zeleny, 2012) is based on three vital phases: "productiongrowth-destruction", "crisis-action-catharsis", "birth-life-death" and so on, depending on the field of discussion. It is a creation of the new and unprecedented phase of renewal or rebirth. The duration differs according to sector or industry which can span over long period of time; the R \& C cycle in technology is quite rapid. Drucker, 1993 identified four major transitions in the global economy: "In the 1300s, the transition from feudal agrarian economy to modern Capitalism and the

\footnotetext{
${ }^{1}$ Department of Management and Marketing,Faculty of Management and Economics, Tomas Bata University in Zlin, Zemědělská 1, 61300 Zlin, Czech Republic, e-mail: otekhile@gmail.com

${ }^{2}$ Graduate School of Business, Fordham University New York City, NY, USA, e-mail: mzeleny@fordham.edu
} 
nation state; in the late 1700s and 1800s, the Industrial Revolution of steam power and factories; a Productivity Revolution as management of work and processes boosted the productivity of labor, transforming the proletariat class into the middle class; and since the 1990s, the emergence of the Knowledge Economy".

Karl Marx, a revolutionary and critic of capitalism claimed that the elimination of labour by technology during the industrial revolution would lead to accumulation of capital which will in turn result in massive unemployment and a fall in wages invariably causing decreases in consumer demand and profits. (Dyer-Witheford, 1999; Wendling, 2009). To the extent that workers are alienated from the object of produce and adversely, the increase in accumulation of capital, causes industries to over produce. This over-production eventually leads to reduction of work force or decrease in wages. He sees machines as an opportunity to free man from the rigor of routine works, to shorten labour time.

SSTs are transforming different industries and sectors of the economy, from ATMs in banking to ecommerce in the travel industry which is resulting in significant cost reductions for businesses and outsourcing of services to customers. The services are shifted to the consumers in the form of better services and lower prices. Business organizations both small and large, all around the globe are seeking to be innovative and improving their products and services in order to have competitive advantage and to remain profitable. Such technologies previously caused an increase in productivity growth rate and an improvement in the quality of life. On the consumers' side- consumers seek better, well-designed, customized products and services and speedy delivery at the lowest possible time and at reasonable and fair prices. Nye, 2006stress that "technology is not something new, it is more ancient than the stone circles at Stonehenge". It has been part and parcel of human society as far back as archaeology

According to Li Keqiang, the premier of China, in his speech at the World Economic Forum, 2015, he mentioned that in a small village in China of about 700 households, they were over 2,000 registered online stores. More and more small entrepreneurs are operating online stores from all over the world, thereby having direct contact with consumers. The role of the middlemen is fast becoming eliminated (disintermediation). The factor encouraging this trend towards a self-service economy is quick innovation which leads to cheaper and simpler capital machinery. The aim of this paper is to examine the cause of the growing unemployment rate focusing on the Self-service technologies impacts. This paper is divided into four sections: the first section deals with the introductory part, the second section gives a theoretical background and review of related literatures. The third section focuses on the long term unemployment in the United States and E-28, identifying where the jobs went. The last part draws conclusions.

Theoretical Overview and Empirical Evidence

\section{Definition of Self Service Technologies}

Castro, Atkinson and Ezell (2010) identify self-service as process of shifting services to the consumers is that the consumers are given the opportunity to do the scanning, bagging and paying for the products or service, customized the products to his taste and so on. Zeleny (2009) claims that the self-service process often involves technology (machine or computer) used in transforming inputs (materials, information or service) into products which could be physical goods, services or information. It is seen as a "package of hardware, software, brainware and the support net." Ultimately, it is used for achieving a certain purpose or goal. Self -service technologies (SSTs) are technological interfaces that enable customers to produce a service independent of direct service employees' involvement. Examples include automated teller machines (ATMs), Vending machines, banking by telephone, automated check-out kiosk at airports and hotels and services over the 
internet. (Meuter, Ostrom, Roundtree, and Bitner, 2000). These SSTs usually makes businesses continuously available for the consumers' convenience and comfort.

\section{Types of self-service technologies}

There are several self-service technologies nowadays; more and more new SSTs are being invented while old traditional SSTs are improved upon. Castro, Atkinson and Ezell(2010)point out several types of self-service including electronic kiosks, internet applications, mobile payments such as Online-Banking, Online- Health, E-learning, Retail E-Commerce, Online Customer Service, Online Customization, E-tickets and even E-Government. The electronic kiosk provides users personal services and access to information. And due to innovation, there are touch screen displays and user friendly interfaces. These self-service kiosks can be found in shopping malls, airports etc. ATMs (or bankomat) which was one the earliest SSTs introduced in the 70s, is increasingly being used all over the globe.

Another example of electronic kiosks is self-service gasoline stations. These gas stations are without attendants and allow customers to pump gas by themselves and in some places customers make payment for the gas using a self-pay option. In the United State of America, New Jersey and Oregon revolted against self-service gas stations due to the perceived negative impact they have labour market. But this made the price of gasoline 2-5 cent per gallon higher than in other States. Also there are self-paying car parks which allow motorists to pay for parking using a credit card, debit card, smart card, or cash without the use of an attendant. Automated Vending Machines can be found in schools, shopping malls, and train stations.

In addition, there is the transit systems used in Washington, D.C.; which allows travellers to simply pass a contactless smart card over a reader to pay their fare and board a bus or to enter the subway. In some countries rather than using smart card, travellers can use their cell phone as a payment devise. Recently some fast food restaurants and convenience stores have begun implementing selfservice kiosks to improve business and provide better service to their customers. For example, Subway is piloting 70 self-service kiosks in its sandwich shops for customers to place their order and pay for their meal. The kiosks can be installed at the restaurant or in a satellite location so that customers can place an order for pickup or delivery.

The travels and the hospitality industries are not left out of this technological innovation. The online check-in of passengers and coupled with the self-check in /check- out kiosk used in some airports around the world like the United States of America have enabled airlines to reduce or eliminate the cost of processing using an airline agent. The cost of checking in a passenger with an airline agent is approximately $\$ 3$ versus only $\$ 0.14$ with a kiosk. Some hotels are beginning to allow guests to avoid lines and check in at kiosks that can look-up a reservation, allocate a room, and dispense a room key. They also offer automated check-out, for example, through a dedicated electronic kiosk in the hotel lobby (where guests can print a receipt) or through an application accessible through the in-room TV, so that travellers can more easily complete their stay. Self-driving cars or driverless could be available in 2020. Already four U.S. states and Washington D.C. have passed legislation allowing driverless cars. Such technology will render some drivers jobless.

\section{Definition of Unemployment}

The definition of unemployment according to ILO; adopted by the 13th International Conference of Labour Statisticians (Geneva 1982): The unemployed can be defined based on three criteria. Those who are not in any kind of paid employment or self -employment. Secondly, those who are available to work either in paid employment or self-employment but who are not in employment within the stipulated period. Thirdly, those who are "actively seeking work" by taking active 
positive steps by registering in the job agencies, applying for jobs through placement of job adverts on newspaper or internet or seeking assistance from friends or relatives and yet they are unemployed.

In addition, based on the resolution adopted at the $19^{\text {th }}$ International Conference of Labour Statisticians, October, 2013 concerning statistics of work, employment and labour underutilization (paragraph 47-48). The definition was extended to include the following:

a) future starters, "not in employment" and "currently available" who did not "seek employment" as specified above, because they have already made arrangement to start a job within a short period, set according to the general length of waiting to start a new job in the nationalcontext usually not more than three months

b) Those who are undergoing skill training programme or retraining scheme within the employment promotion programmes who on this basis are "not in employment", "not currently available" and who "do not seek employment" because they have a job offer to start within the three months

c) Those who are "not in employment" expecting or waiting for opportunities to travel (migrate) abroad in order to work for pay or profit.

d)

\section{Classical view on Unemployment}

The classical economists believed that unemployment arises due to the obstruction in the functioning of the labour market because they see the market as a "single and static market" which is characterized by "perfect competition, spot transaction and institutions for double auction bidding". The government should not intervene in the economy because the economy can correct itself in the long run. The labour market consists of quantity of labour demanded and supplied which are brought into equilibrium by the fluctuations in the wage rate; at the point of intersection the equilibrium real wage rate and full employment is determined. There is no incessant unemployment above the frictional level. Unemployment is voluntary, it arises as a result of too high real wages and involuntary can occur if the government requires the employers to pay a minimum wage above the labour market rate. This theory depends on the smooth and fast adjustment of the labour market. (Ackerman et al., 2013; Mouhammed 2012). The classical model is focused on the supply side while the Keynesian model is focused on the demand side.

\section{Keynesian's view on Unemployment}

The Keynesian unemployment theory emanates from the publication "The General Theory of Employment, Interest and Money" by John Maynard Keynes (Keynes, 1936). This Keynesian unemployment theory is also referred to as "cyclical unemployment". The unemployment which characterized the great depression in the 1932, it is acclaimed by the classical economists as caused by the refusal of labor to accept money wage reduction. Keynes opposed the classical economic theory by emphasizing that the government should intervene in the managing of the economy because he believed that if the economy is left to correct itself it may take a long time and before then "we are all dead". The Keynesian theory was developed at the beginning of the "great depression". He proposed an increase in "Aggregate Demand"; if overall spending is high, there will be increase demand for goods and services then employers are encouraged to produce more and employ more workers to satisfy the additional demand. Invariably aggregate demand reduces unemployment. Unemployment is seen as a deviation from its natural rate (5.5 percent) around which the unemployment rate fluctuates. This is caused by the downturn in the economy. What is true of average worker is also true for the governments; in this present times when persistent unemployment is forcing governments to provide relieve for the unemployed from tax payer's money or borrowed funds 
$A D=C+I+G+(\mathrm{X}-\mathrm{M})\{$ Full employment $\}$

Where AD is Aggregate Demand

$\mathrm{C}$ is Household Consumption

$\mathrm{G}$ is Government Spending

$\mathrm{X}$ is Export

$\mathrm{M}$ is Import

\section{Literature Review}

There is an increasing concerns and arguments that rapid innovation of technologies which leads to increase in productivity growth rate is fast relieving workers of their jobs. Since the 2008 economic recession, there has been a "persistent unemployment". Technological unemployment was widely cited as a problem in the 1920s and 1930s, a period during which productivity soared higher, inequality and unemployment were high and instability was the norm. From recent empirical evidences, an increasing level of technological unemployment is a problem spreading across the advanced economies of the world and which will eventually hit developing economies like "Tornado" (The Economist, 2011; 2014)

According to the NBC News President Obama explained that the reason companies are not employing is not because of his policies, it is because the economy is so automated. And that "There are some structural issues with our economy where a lot of businesses have learned to become much more efficient with a lot fewer workers. You see it when you go to a bank and you use an ATM, you don't go to a bank teller, or you go to the airport and you're using a kiosk instead of checking in at the gate." The present unemployment maybe attributable to the short run consequences of rapid technological advancement.

Shah and Mehta (1998) explore the impacts of technologies on the global workforce and the world economy. Several issues like gainers and losers of information technology and competitive advantage of skilled workers which would be of concerns in the $21^{\text {st }}$ century. Labour will not be expressed based on workers' level of education and job experience but will be expressed on the basis of technical knowhow and technology. There will be high demand for skilled workers in business organizations; adversely there would be global increase in unemployment. Business organizations are fast changing, re-engineering and restructuring to adapt to rapid technological innovation which often leads to downsizing. In the light of this, a lot of jobs are lost mostly unskilled workers are laid off. The productivity of businesses will increase, cost of production reduced. Consumers will enjoy wide variety of goods, quality and speedy delivery of services.

Brynjolfsson and Mcfee $(2011 ; 2014)$, argue that the rapid changes in technologies with sophisticated technologies have made more companies to discover or invent better ways to produce products and provide services to their customers. These innovative technologies are disrupting the labour market by displacing existing workers and making them redundant. But unfortunately the creation of new businesses is not happening at the same pace, fast enough to absorb or employ the workers displaced. Computerization is no longer confined to a particular sector and to routine jobs but rather have encroached into the domain of human skill. Development which seems impossible a few years ago like fully automated cars, high quality computerized translation are now realities or will be soon. By and large these ongoing innovations should yield great benefits to humanity but however in the meantime, these developments are likely to significantly leave some people worse off. In order for the economy to take full advantage of this rapid change in technology, there must necessarily be reform in education and increased investment. 
Jones (2012) further attributes advancement in technologies in the area of medicine as responsible for increase in life expectancy. People are now living longer and working longer beyond the retirement age. And due to the 2008 economic downturn which resulted into loss of retirement savings, many people within the retirement age bracket may wish to continue working. At the lower end of the spectrum there is likelihood that it may cause increase in youth employment. In essence when older people work longer, there are fewer jobs vacancies. In addition, with the rapid innovation of new technologies like robotic and artificial intelligence (AI), the number of jobs would be swallowed up. Initially new technologies are supposed to create jobs, for example the driverless trains constructed in 1998 in France. The tide is fast changing, before it used to be low skilled jobs that are the most threatened by technology. A widening range of jobs is now being done by robots in traditional white collars occupations and the traditional jobs have shrieked. However, the continuous growth in productivity brings overall benefits to the society at large but in the short run, it can result into loss of jobs for a group of people who are low skilled and will demand a lot of struggle and sacrifice. In the long run the productivity growth does not increase unemployment. (Rezai\&Semmler, 2007; Jones, 2012).

Zeleny (2012) further describes the corso and ricorso of the economic sectors due to the accelerating impact of the productivity growth rate. The three major sectors (Agriculture, Industry and Service) in the developed countries have reached their peak in terms of the percentage of workforce employed (see figure 3). There has always been a new sector emerging to absorb the employment slack of the previous high productivity sector. The new sector the Government Welfare Unemployment (GWU) has emerged in developed countries to absorb the unemployed. This sector is financed by tax payers' money, however, the growth of this sector in unsustainable and has resulted into unbridled spending, high indebted, unbalanced budgets and out of control incomes.

Frey and Osborne (2013) examines the susceptibility of jobs to the computerization; using a novel methodology to estimate the probability of computerization for 702 detailed occupations. The future impact of computerization on the US labour market is analysed to the estimates the number of jobs at risk. According to the estimates about 47 percent of the total US employment is at risk. Educational attainment and wages exhibits a strong negative relationship with the probability of computerization. As technology advances, low skilled workers will be reallocated to tasks that are non-susceptible to computerization-i.e. tasks requiring creative and social intelligence. For workers to win they would have to acquire creative and social skills.

Marchant, Stevens and Hennessy (2014) stresses that the rapid innovation of technologies that are displacing human beings of work presents both risk and opportunities. These technologies exhibit the potentials to enrich our lives and free us from drudgery and danger of manual and monotonous labour and enable consumers and businesses enjoy a higher quality of life. The wide spread of chronic technological unemployment could result in unacceptable individual and societal instability and adversity. Therefore, policies must evolve as quickly as the technologies changes. Based on this, it is ultimately important and appropriate to identify policy options to address these potential problems. An inventory list of possible policy options aimed at addressing this technological unemployment would be provided online and updated from time to time.

Castro, Atkinson and Ezell (2010) point out those self-service technologies provides immense benefits to businesses and consumers in form of improved quality of life, convenience and cost reduction. It also has the capacity to contribute to the prosperity of national economy in terms of the per capita income and productivity growth. Therefore, policy makers should not enact policies that will restrict self-service technologies but rather make policies that will stimulate the self-service economy.

Martin Ford the founder of a Silicon Valley based software development firm argue that the acceleration of technology will ultimately invade many industries that have traditionally been 
labour intensive. Furthermore, the process of "creative destruction" will destroy "old industries" and new capital intensive industries will be created while less labor intensive industries will be created. He focuses on the connectivity of economics and technology. The great depression which was basically grasp through the lens of business cycle or financial in origin could possibly be the result of the acceleration of technology. He employs simulation of lights in the tunnel which he used to visualize the economic implications of a new technology that are likely to appear in the coming decades. As a result of this the overall economy will reach a "tipping point". Beyond this point the economy will no longer be able to absorb the workers who lose jobs due to automation. If it is not address by some type of government policies, we will see a precipitous drop in consumer spending as a substantial fraction of the population loses confidence in its future income continuity that of course would result in even more unemployment and a downward spiral would ensue. He challenges all the conventional stance advanced forward for the future and shed more light on the danger that lies ahead if we do not plan for acceleration of technology (Ford, 2014).

In addition, Martin Ford point the impact that accelerating technological advance has on the job market and the overall economy is set to defy much of the traditional belief about how technology and economics relate. One major belief is that which can be refuted is the assumption that automation is basically a threat to unskilled workers. This assumption stern from the fact that such jobs are monotonous in nature. Today it is a different ball game, as skilled workers will be affected. They will discover that their jobs will soon be automated. (Ford, 2015).

Contrarily, Bassen 2015 presents the relationship between technology and occupations. Based on the empirical findings, he emphasised that the jobs which are automated or computerized is growing faster; more employments are created. There is a shift of employment towards occupations which are computerized. It is easy to pin point jobs like telephone operators and typesetters which has been lost due to technology advance. Invariably, workers who are skilled in computing and technology are substituting workers who lack such skill. As some jobs are being eliminated so also some jobs are being created. The challenge facing today's laborforce is lack of the needed technological skills to fit into the laborforce and not unemployment.

\section{Long term Unemployment Situation in the USA and EU-28}

The number of unemployed is growing across the globe most especially amongst the youth. It is one of the major concerns of policy makers because of the implications or effects on the economy. Long term unemployment situation in some advanced economies remains high. (Figure 2). In Europe, 2014 Greece has the highest unemployment rate of 19.5 percent, followed by Spain with 12.9 percent, Croatia 10.1 percent, and Portugal 8.4 percent. The unemployment situation in the EU-28 was 5.1 percent in 2013 and remain 5.1 percent in 2014; the long term unemployment rate in USA is 1.4 percent in 2014 below 5 percent (Eurostat, 2015). The long term unemployment skyrocketed following the great recession of 2007-2009 and continued to rise after the recession has ended, thereafter plummeted during the labour market recovery. But why are people who are willing to work and have been actively searching for jobs for more than 52 or 99 weeks unable to secure a gainful employment. What is the cause, is it that they lacked the required skills needed to fetch them employment or the jobs are not available within the sectors of the economy to absolve them?

Furthermore, there are divergent views as regards the causes of unemployment. Some economist blame technological changes, some shift the blame on external sources and shocks is that economic downturn or cyclical changes while some argued that the deficiencies in aggregate spending and innovation are the root cause of the problem while some scholars point that it is as a result of skills mismatch or. Keynes John affirmed that the world is suffering from "technological unemployment"; an unemployment which arises from discovery of new means of production by reducing cost. 
Figure 1 Long Term Unemployed as a percent of total unemployed, quarterly averages, 1994-2014

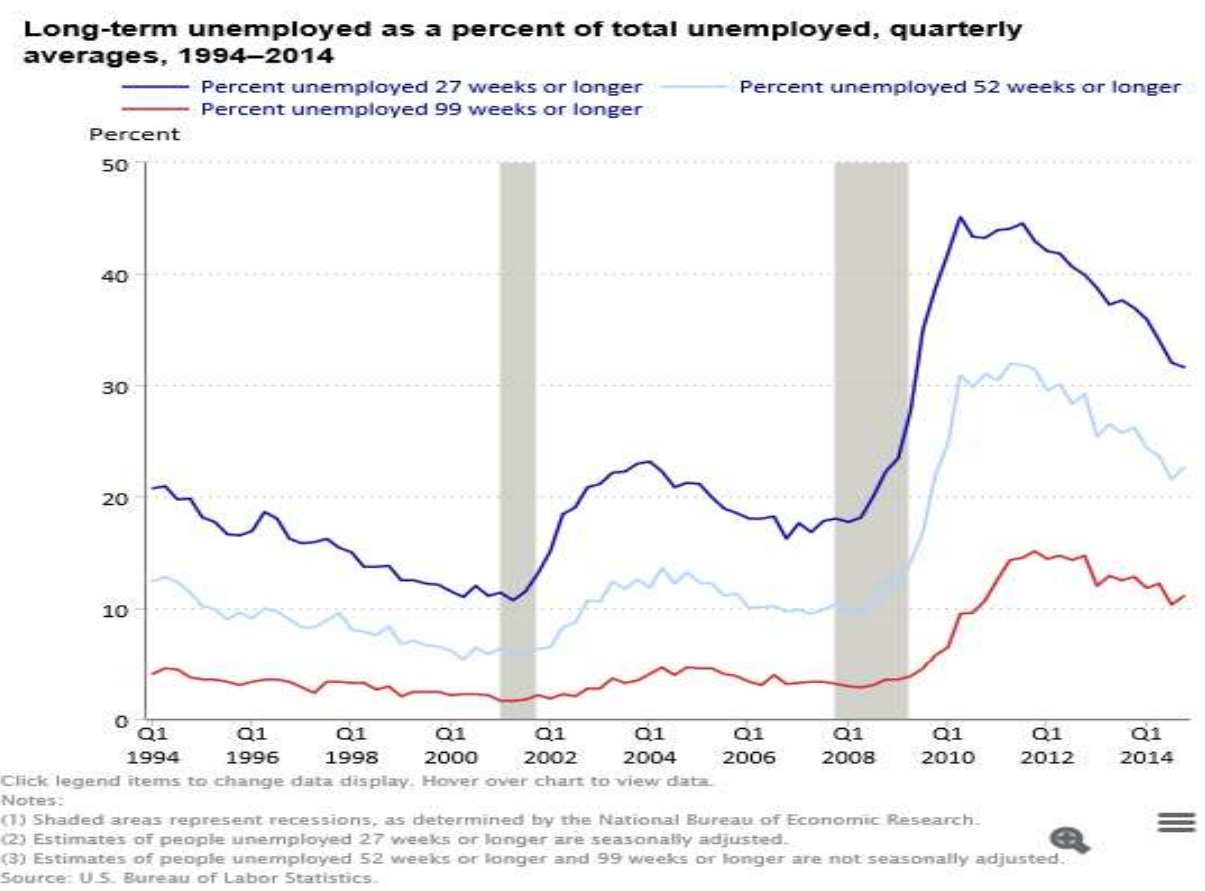

Figure 2 Long Term Unemployment in Some Selected Advanced Economies

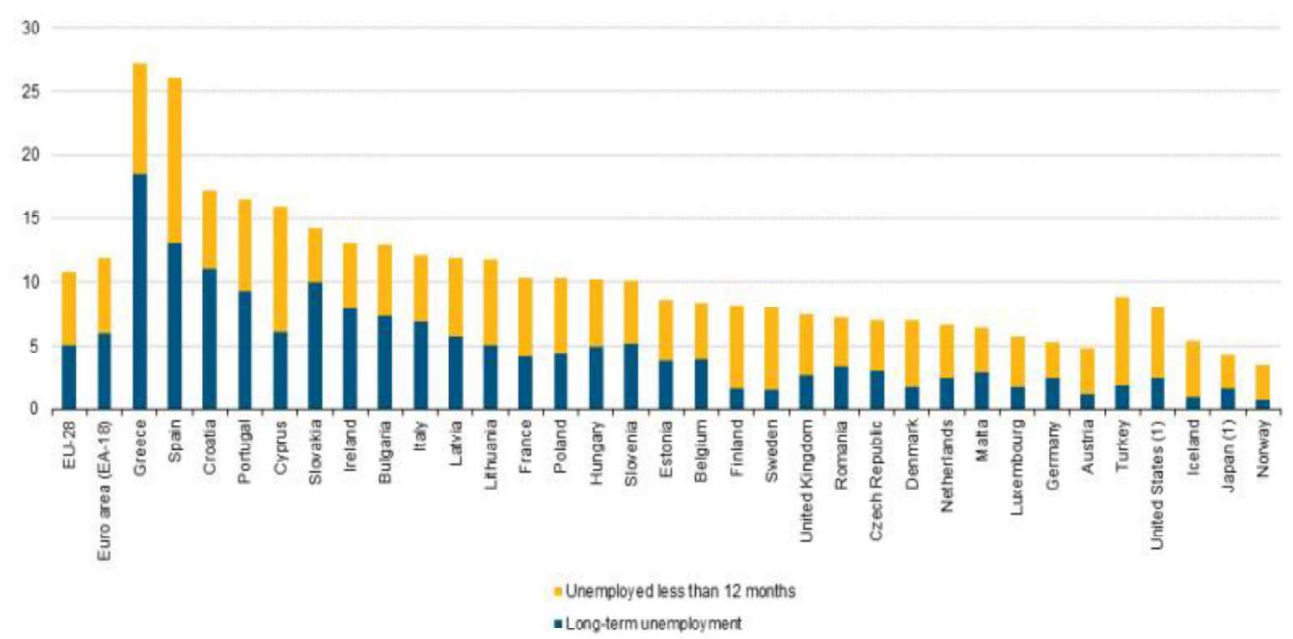

(') 2012

Soucce: Eurostat (online data codes: une__ta and une_ttu_al

Source: Eurostat/Statistics

Where did the Jobs go to?

The jobs that are lost due to the introduction of new technologies, where did these jobs or workers displaced go to? These workers in a way are absorbed by other sectors but in a situation where all the sectors have reached their peak and can no longer absorb these workers. And in a situation where there is rapid advancement in technology which cut across all sectors? Where would these workers go? The only possibility is for a new sector to emerge to absorb them. For example, in the late 1800s about three-quarter of US workers are employed in Agriculture but due to mechanization of agriculture and advancement in technology today the number is around $2-3$ percent. The 
workers displaced in agriculture were absorbed in the Manufacturing and service sectors. Technology advancement eliminated millions of jobs. Undoubtedly, according to the pew research center 2014, new technologies disrupts jobs in the short run but in the long run, this group of displaced workers are absorbed by other sectors (either new or emerging sectors). The net gain of the society in the long run has always been prosperity not job losses.

Zeleny 2012, identifies the new emerged sector in the US and other advanced economies which absorbs the unemployed as the 'GWU'- Government, Welfare and Unemployment. This sector is financed by the tax payers' money and it is not sustainable. All the products and services (consumption) are paid from tax payers' money. Economic sectors are guided with the same C \& R principles; they emerge, grow and decline. Initially agricultural sector builds their industrial, service sectors and GWU and then they gradually lose them production growth. Under the figure, there is no amount of stimulus or quantitative easing which could create self-sustained net job growth in agriculture, industry or services. The reason is simply that there are only basically four thing humans can do: Produce food, Manufacture goods, provide services or depend on the state.

Brynjolfsson and Mcfee (2011), states three alternative stance provided by analysis: The cyclical view holds that the present happening is not mysterious. Unemployment in US remains high simply because the growth of the economy is slow and is not capable of quickly putting people back to work and Paul Krugman is also one of the advocates of this view. The deep drop in demand like the "Great Recession" is bound to be followed by long and frustrated slow recovery. The second school of thought viewed it as stagnation and, not cyclicality in nature. Stagnation in this context means a long term decline in America's ability to innovate and increase productivity. Economist Tyler Coven articulates this view in his 2010 book, "the great Stagnation": The growth of the median income slowed down significantly at 30 years ago and actually declines during the first decade of the century. The average American earned less in 2009 than it did in 1999 is that the decrease in wage rate. Coven attributes this to the fact that the economy has reached the peak.

In addition, Leo Tilman and Edmund Phelps also agreed with Coven's view. This argument does not ignore the "Great Recession" and does not believe that technology is the principal cause of the slow down. The slow down actually predates the great depression and one way to lift the economy out of this state is through rapid innovation and technical progress. The third view based on the end of work argument of Jeremy Keynes John Maynard, Management theorist Drucker Peter and Nobel Prize winner WassilyLeontiff support the view of Rifkins, 1995 which is revealed in his hypothesis: "that we are entering into a new phase in the world history-one in which fewer people will be needed to produce goods and services and more sophisticated software technologies are going to bring globalization even closer to a near "workerless world". Today, all sectors are experiencing technological displacement forcing millions onto the unemployment roles, coping with this challenge will be the most pressing social issue of the coming century".

OECD, 2014 present based on empirical evidences from in the past decade that the demand for more skilled workers is fast surpassing the demand for low skilled workers with the share of total employment in managerial and technical and professional jobs is increasing. There is a shift of Employment from unskilled labor towards high skilled labor. These changes may aggravate in the face of rapid technological advance and diffusion of ICT and could result into more displacement of routine jobs. Since the financial or economic crisis, the unemployment rate has remained high in G20 countries and in some countries the high unemployment rate predates the economic crisis and the present challenge is to prevent it from translating into structural unemployment.

Fig 3 Long term sector employment dynamics in the USA

$\mathrm{G}=$ Government $\quad \mathrm{S}=$ Services $\quad \mathrm{I}=$ Industry $\quad \mathrm{A}=$ Agriculture 


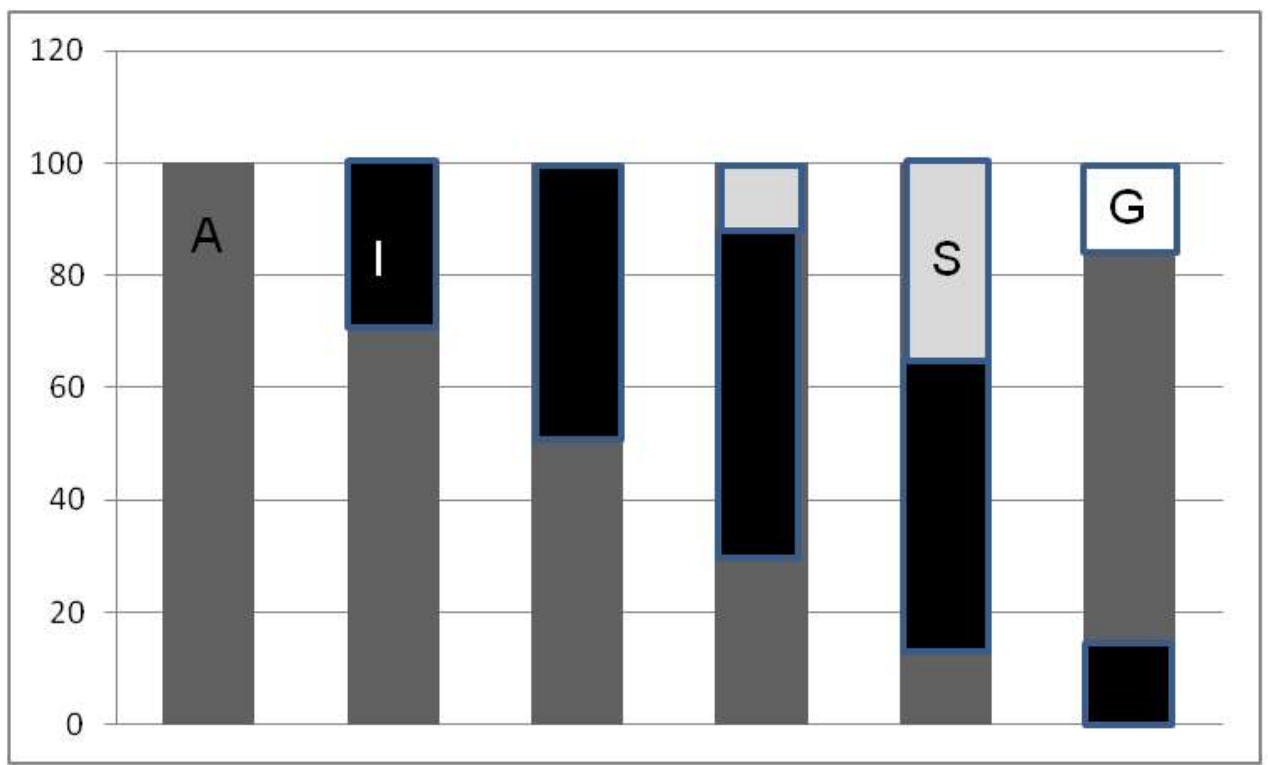

Source: Adapted from Zeleny, 2012

\section{CONCLUSION}

New technologies especially self-service technologies are fast changing the conventional way of doing businesses across the globe and shifting some producers' responsibilities to the consumers. And its emergence like any other technology advance presents both risk and opportunities to the overall national economy as increasing number of low skilled workers are being displaced as the rigorous routine work are automated. Although these self-service technologies have the capacity to improve the quality of life and production growth. It is not sufficient to based our arguments on the fact that technological advance is fast displacing unskilled labor and invariably causing unemployment and much more we cannot completely refute the reality and claim that self-service technologies are dramatically transforming our economies and fast displacing low skilled workers due to the alarming rate of unemploymentin these advanced economies. No doubt, the continual improvement of technology often results in increase in productivity growth rate. With the automation of the major sectors of the Agriculture, Industry and Services, more and more unskilled workers have been displaced. Low labor intensive and high capita intensive can be used by industries to produce more.

The evidences from the metamorphosis or transformation of the major economic sectors over the decades, it is no gainsay that these major economic sectors have reached their peak and can no longer absolve the teeming unemployed due to high productivity growth rate and the public sector is not sustainable neither in terms of creation of employment. For example, the US Agricultural sector only employs 0.5 percent of labour. (Zeleny, 2012). One feasible solution is not making appropriate structural policies or increasing aggregate demand but it is the emergence of a new sector to absolve the teeming unemployment in the advanced economies.

\section{ACKNOWLEDGEMENT}

The author wishes to acknowledge the support of this work by the Internal Grant Agency, Tomas Bata University in Zlin IGA/FaME/2015/039 


\section{REFERENCES}

Ackerman, F., Goodwin, N., Nelson, J., Welsskopf, T., \& Institute, G. (2013). Theories of Unemployment. Retrieved from: http//www.eoearth.org/view/article/156591

Bessen, J. E. (2015). How Computer Automation Affects Occupations: Technology, Jobs, and Skills. Boston Univ. School of Law, Law and Economics Research Paper, (15-49). Chicago Brynjolfsson, E., \& McAfee, A. (2011). Race against the machine: How the digital revolution is accelerating innovation, driving productivity, and irreversibly transforming employment and the economy.

Brynjolfsson, E \& McAfee, A (2014). The Second Machine Age:Work, Progress, and Prosperity in a Time of Brilliant Technologies. WW. Norton \& Company, New York.

Castro, C., Atkinson, R., \& Ezell, S. (2010). Embracing the Self Service Economy

Drucker, P. (1993). Innovation and Entrepreneurship: Practice and Principle. Harper Collins Publishers. ISBN 0-88730-618-7

Dyer-Witheford, N. (1999). Cyber-Marx: Cycles and circuits of struggle in high-technology capitalism. University of Illinois Press.

Frey, C. B., \& Osborne, M. A. (2013). The future of employment: how susceptible are jobs to computerisation?

Ford, M. (2009). The light in the tunnel: Automation, Accelerating Technology and the Economy of the Future.

Ford, M. (2015). Rise of the Robots: Technology and the Threats

Gerber, E.M. \& Martins, C.K. (2012). Supporting Creativity within web based services. Internal Journal of Design 6 (1), 85-100

Keynes, M. (1936). The general Theory of Employment, Interest and Money. London: Macmillan, 1936.

William, C., et al (2011). Theorizing the Self Service Economy: A case study of do-it -yourself (DIY) activity. Journal of Economy and its Applications. Volume 2, Issue 1, Pages 1-26.

Li Keqiang (2015). Premier of People's Republic of China Speech at World Economic Forum Annual Meeting, Davos 23 January.

Nye, D. E. (2006). Technology Matters: Questions to live with (pp. 6-7). Cambridge, MA: MIT Press

Pew Research Center, (2014). AI Robotics and the Future of Jobs.

Murphy, S. (2009). The growth of self-service. Chain Store Age, 85(12), 44.

Meuter, M. L., Ostrom, A. L., Roundtree, R. I., \&Bitner, M. J. (2000). Self-service technologies: understanding customer satisfaction with technology-based service encounters. Journal of marketing, 64(3), 50-64.

Marchant, G. E., Stevens, Y. A., \& Hennessy, J. M. (2014). Technology, Unemployment \& Policy Options: Navigating the Transition to a Better World. Technology, 24, 1.

Mouhammed, A.H. (2012). Important Theories of Unemployment and Public Policies. The Journal of Applied Business and Economics, 13(2), 156.

OECD, 2014. Preventing Unemployment and Underemployment from becoming Structural.

Schumpeter, J.A. (1942) Capitalism, Socialism and Democracy, Harper \& Row, New York, 1942. International Labour Organization. The definition of Unemployment.

ILO, "Report and proposed resolution of the committee on work statistics", $19^{\text {th }}$ International Conference of Labour Statisticians, Committee on Work Statistics, Geneva, 2 November-11 November 2013.

Rezai, A., Semmler, W., \& Chen, P. (2007). Productivity and Unemployment in the Short and Long Run. Policy Note. SCEPA Working Paper 2007-8, Schwartz Center of Economic Policy Analysis.

The Economist. (2014). Technological Unemployment: Race Against Machine, November 19, 2011 The Economist. (2014). Coming to an office near you, January 18, 2014, 7-8.

Zeleny, M. 2009. Technology and High Technology: Support Net and Barriers to Innovation. Advanced Management Systems, 1/1: 8-21. 
Zeleny, M. (2010a). Machine/organism dichotomy and free-market economics: Crisis or transformation? Human Systems Management, 29(4), 191.

Zeleny, M. (2012b). High technology and barriers to innovation: from Globalization to Relocalization. International Journal of Information Technology \& Decision Making. 11(02): 441 456.

Zeleny, M. (2012c). Crisis and transformation: On the corso and ricorso of human systems. Human Systems Management, 31(1), 49-63. 